\title{
TO EXPLORE THE URBAN LANDSCAPE LIGHTING DEVELOPMENT IN CHINA - TAKING THE CITY OF SHANGHAI AS AN EXAMPLE
}

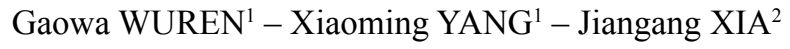 \\ ${ }^{1}$ University of Science Technology Beijing, 100083, China. \\ E-mail:60216@163.com \\ ${ }^{2}$ Beijing Institute of Defense Science and Technology, Beijing, 100094, China. \\ E-mail: bzhiwsmd@163.com (corresponding author)
}

\begin{abstract}
Landscape lighting is a symbol of modern urban development and service capabilities, and it is also the important content of urban competitive power. This paper used the descriptive statistics, basic statistical tests and Granger causality test to analyze the historical data and the data from the Shanghai Landscape Lighting Survey. It draws conclusion that Shanghai's landscape lighting has formed unique and sustainable development mode with governmental, cultural, economic, social and ecological attributes, which is led by the government, and market and society join together in the construction and operation.
\end{abstract}

Keywords: urban landscape lighting, Shanghai, distinctive characteristics

\section{INTRODUCTION}

Foreign and domestic studies show that urban lighting contributes greatly to urban development, helping to ensure the city's security, image, economic growth and full employment (Willis et al. 2005). Henderson et al. (2010) used satellite data to study the relationship between city lights and economic growth or income growth. They found that establishing city lights contributes to economic growth, and economic growth in turn also seems to contribute to further development of city lights. Construction practice also shows that the urban landscape lighting plays a significant role in urban economic development, especially in the night market economy. Lyon, France, which as the 'Festival of Lights' attracts more than 300 million visitors annually, and has generated revenue amounting to about ten million Euros; Netherlands' 'Lighting Capital', Eindhoven, due to its land- 
scape lights, jumped from being a small village after World War II to the fifth largest city in the Netherlands, and one of the world's leading cities (Dubovecak 2010).

City lights in Shanghai were introduced in 1882, the third year after Edison first invented the incandescent lamp (Lu 1998). Light was an essential factor in the development of the international metropolis from the1930s, when 'Night in Shanghai' was famous in the Far East. In 1989, Shanghai was the first city to start a large-scale renovation and expanded construction of landscape lighting, for example in the Bund and Nanjing Road shopping street (China Illuminating Engineering Society [CIES] et al. 2002), which has been unanimously praised by tourists at home and abroad, and contributed significantly to the economic development of Shanghai. At present, the length of Shanghai's landscape lighting line has reached $140 \mathrm{~km}$, covering an area of over 100 square kilometers. The 17 districts and counties of Shanghai include 4,283 areas of landscape lighting, with 67,370 kilowatts of total assembly power, and an average district power of 3,963 kilowatts according to data from the Shanghai Landscape Service Centre, Greening and City Appearance Bureau, which by the end of 2013 covered about 90 percent of Shanghai's landscape lighting. In terms of its manifestation, volume, or trend, Shanghai's landscape lighting reflects the times, and keeps pace with international standards, leading developments in landscape lighting. Shanghai, with its remarkable achievements made in landscape lighting, made history by becoming the only Asian member of Lighting Urban Community International (LUCI) when it was first established.

However, there have not been any systematic studies regarding the significance of landscape lighting for the economic or urban development of Shanghai, mostly due to the lack of appropriate data. At the same time further uncertainties for long-term stability have been introduced due to the multitude of diverse construction projects with specialized themes which make long-term maintenance and management as a whole difficult to coordinate or guarantee. Using time series data, this paper analyses the impact of the introduction and development of city lighting on economic development and, after summarizing the operation mechanisms for Shanghai's landscape lighting, provides some suggestions for other cities.

\section{DATA AND METHODS}

This study uses data from Shanghai Statistical Yearbook (2005-2013) and Shanghai Landscape Lighting's Performance Evaluation \& Long-term Operating Mechanism Survey. For analytical purposes, it uses descriptive statistics, basic 
statistical tests and the Granger causality test to analyze the five main characteristics of Shanghai's landscape lighting, which are governmental attributes, economic attributes, cultural attributes, social attributes and ecological attributes.

In order to summarize the attributes of Shanghai's landscape lighting, descriptive statistics and basic statistical tests are used in the following and the third section of the paper. The survey data are collected through the method of interview and questionnaire inquiries from all the 17 districts' and counties' lighting offices in Shanghai, which includes capital investments, construction types, ownership, etc. In addition, Shanghai citizens' and visitors' views and evaluation of landscape lighting were explored through questionnaires (310 questionnaires disseminated with 301 returned and valid, including 154 for residents and 147 for visitors).

Granger causality test is also used because it has clear advantages to explain the causal relationship between things (Granger 1969; Pang and Chen 1999; Yi 2006). By testing the causality of some tourism related data from Shanghai Statistical Yearbook with Shanghai's landscape lighting's gross investment in the years of 2004-2012, this paper discloses landscape lighting's contributions to tourism and economic development.

\section{THE DISTINCTIVE CHARACTERISTICS OF SHANGHAI'S LANDSCAPE LIGHTING}

Shanghai has the reputation of 'Far East Ever-bright City', taking its place in the front ranks of world landscape lighting. The floodlighting of exotic building clusters in the Bund, the commercial lighting of Nanjin Road, and the New Year Light Show all add luster to Shanghai's image, tourism and service industry. And with respect to Chinese characteristics, Shanghai's landscape lighting has its unique features. Shanghai is an international megalopolis well-developed in economy, finance and information, so its landscape lighting's main tone is modern and bright (CIES et al. 2002). With China's reform and opening up, Shanghai's landscape lighting is becoming more gorgeous, reflecting its progress in governmental, economic, cultural, social, ecological and other aspects as presented and discussed below.

\subsection{Governmental attributes}

Shanghai's landscape lighting was started at the $40^{\text {th }}$ anniversary of the founding of the People's Republic of China (CIES et al. 2002). Subsequently, the First East Asian Games, the $8^{\text {th }}$ National Games, the $5^{\text {th }}$ Fortune Global Forum, the $9^{\text {th }}$ 
Asia-Pacific Economic Cooperation (APEC) Meeting, and the 2010 Shanghai World Expo among other activities were events that all generated additional possibilities of developing urban landscape lighting. Specially, because of the APEC Meeting in 2001, Shanghai organized a large, dynamic light show named Asia Pacific Development by using high-power lights for the first time in the Bund (Shanghai Statistical Bureau 2002). In the Six-Party Talks in 2006, Shanghai built a new large scale landscape lighting mainly along Huangpu River and in Hongqiao District, and also held a giant landscape lighting performance called Peace Imagination, which attracted many tourists at home and abroad (Xiao 2006). At Shanghai World Expo's opening ceremony, the successful implementation of an extensive lighting show left a memorable impression to people all over the world (Chen 2010).

Major activities provide excellent opportunities for Shanghai to set off upsurge of landscape lighting construction, which can be proved from basic statistics of investments in construction obtained from the survey, presented in Figure 1. It shows that Shanghai's landscape lighting enters a new period of development since the $21^{\text {st }}$ century, and its investment in construction presents an obvious tendency of wave and jump, which has four small climaxes, respectively, in the year of 2000, 2003, 2006 to 2007 and 2009 to 2010, corresponding to Shanghai's major events, such as 2001 APEC Meeting, 2006 Six-Party Talks, 2010 World Expo and so on. Especially in 2009 and 2010, Shanghai government invests 300 million and 443 million for Shanghai Word Expo, respectively.

\subsection{Economic attributes}

Economic development is the main motivation for the development of urban landscape lighting (Gao 2007). Tourism can extend the time of activities with the help of nightscape lighting projects (Guo et al. 2011). To analyze the relationship between Shanghai's landscape lighting and tourism, we acquired data from the Shanghai Statistical Yearbooks, along with questionnaires answered by 17 districts' and counties' lighting offices in Shanghai. In the process of analysis, all indexes can take second-order integrated, one-period-lagged, and reject the null hypothesis when $\mathrm{P}$ is less than 0.05 . Results show that the total investment of landscape lighting (abbreviate to INVEST, including investment in construction, operation and management) is Granger Cause to Tourism Value Added (TVA), domestic tourists' Per Capita Consumption Expenditure in Shanghai (CE) and international tourist Foreign Exchange Earnings (FEE). Moreover, INVEST also acts as Granger Cause to star-hotels' average room occupancy rate (ROR), and has equilibrium relationship with their turnover. See details in Table 1. 


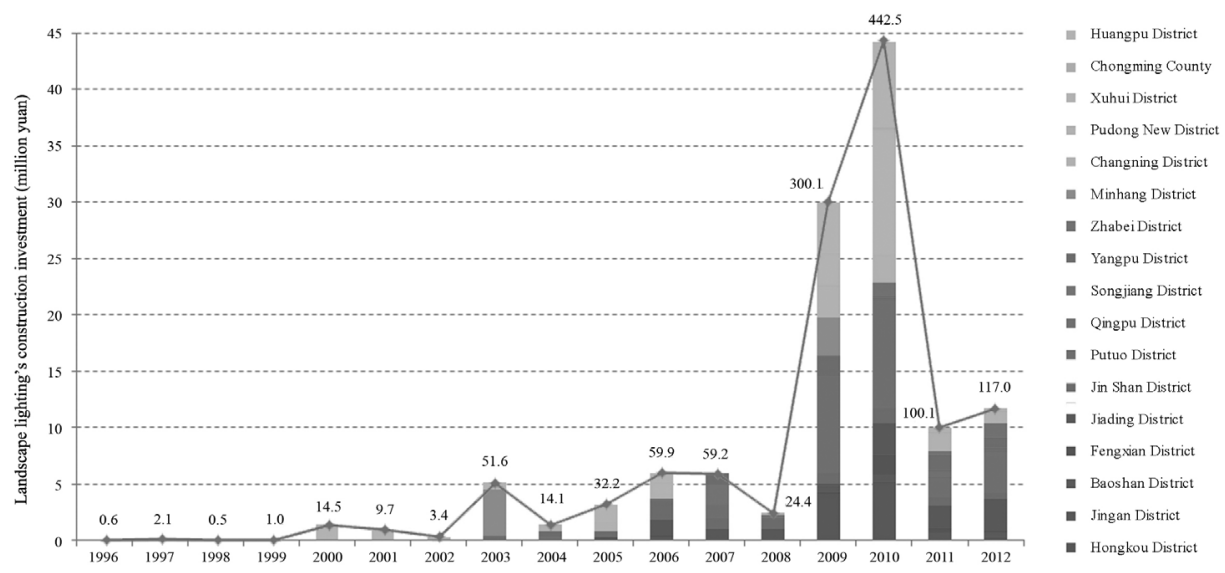

Figure 1. Gross investment of Shanghai's landscape lighting, covering all the 17 districts and counties, 1996-2012

Source: The authors; data from questionnaire of Shanghai Landscape Lighting's Performance Evaluation \& Long-term Operating Mechanism Survey, including all the 17 districts and counties.

Table 1. Results of Granger Tests

\begin{tabular}{lcc}
\hline Null Hypothesis & F & P \\
\hline INVEST does not Granger Cause TVA & 16.2134 & 0.0275 \\
INVEST does not Granger Cause CE & 17.9038 & 0.0242 \\
INPUT does not Granger Cause FEE & 15.0161 & 0.0304 \\
INPUT does not Granger Cause ROR & 20.6798 & 0.0199 \\
\hline
\end{tabular}

Note: if $\mathrm{P}<0.05$, null hypothesis is Tejected, Otherwise accepted.

Source: The authors; estimated from the raW data of Shanghai Statistical Yearbook (2005-2013).

Landscape lighting also has positive effects on nighttime economy. Since 1992, when landscape lighting was developed in Nanjing road and Huaihai road, the closing time of shops' were extended to 10 p.m. Night market sales makes up to about $40 \%$ of the whole day sales and this ratio might be even higher during the weekends (Wang 2010). Furthermore, evening and night time tourism in the Zhouqiao Old street, located in Jiading District, shows an increasing trend, which is more than $80 \%$ of total turnover of the district in 2008 (see Figure 2). 


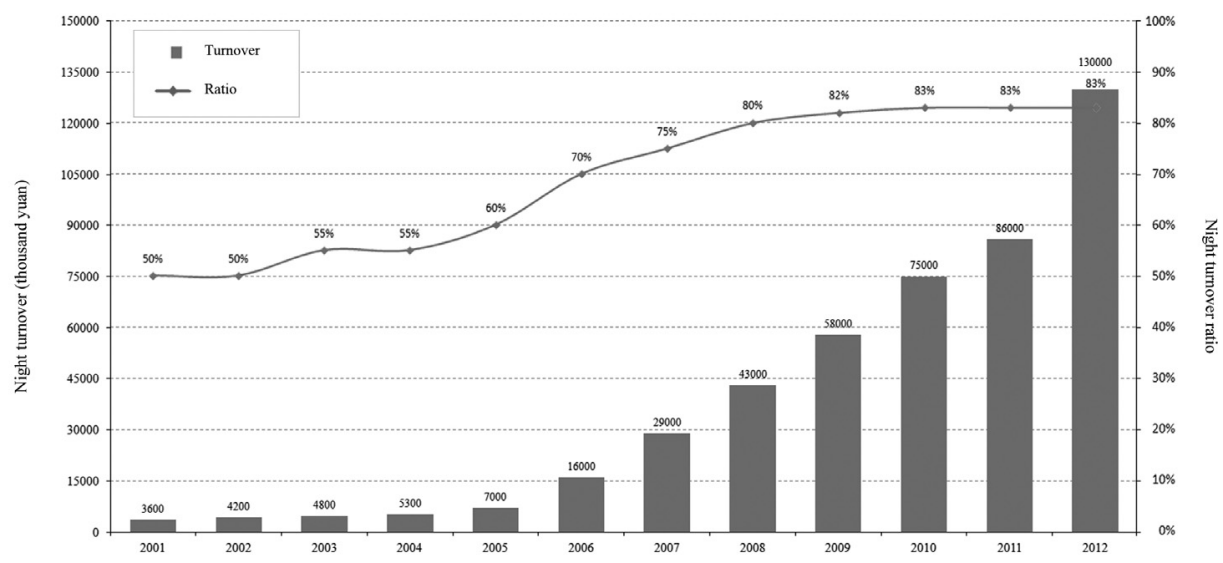

Figure 2. Jiading District's Zhouqiao Old Street's night turnover and its ratio of total turnover, 2001-2012

Source: The authors; data from Jiading District's landscape lighting questionnaire of Shanghai Landscape Lighting's Performance Evaluation \& Long-term Operating Mechanism Survey.

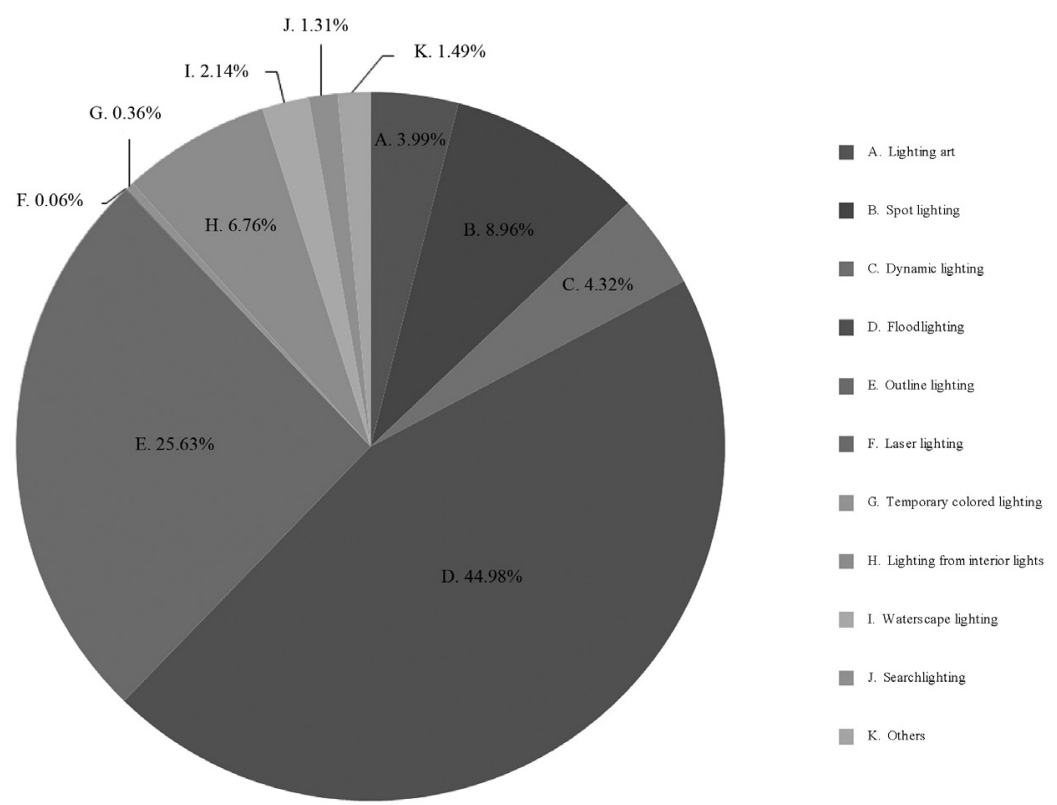

Figure 3. Composition of Shanghai's landscape lighting, including 11 forms (calculation unit is power)

Source: Landscape Service Center, Shanghai Greening and City Appearance Bureau, by the end of 2013, data covers almost all the Shanghai's landscape lighting. 


\subsection{Cultural attributes}

Due to the fusion of Chinese and Western cultures, Shanghai has formed its own unique Shanghai-style culture ('Haipai' in Chinese). Nowadays, Shanghai urban landscapes' characteristics of neutralization and compatibility (Jiang 2006) are not only highlighted by row upon row of buildings, but also reflected in its landscape lighting with different patterns and shapes. As evident in Figure 3, Shanghai's landscape lighting has rich forms, such as floodlighting, outline lighting, facade lighting, search lighting, waterscape lighting, laser lighting, lighting from interior lights and so on. Integrating Chinese nation's features with the essence of many international metropolises' landscape lighting, Shanghai develops its unique 'Haipai' nightscape characteristics of all-embracing and equitable, suiting both refined and popular tastes.

Shanghai's landscape lighting has formed several light groups with distinctive characters mainly because of the different types of architectures (see Table 2). According to the survey, floodlighting using sodium lamps and metal halide lamps is the most common with the largest amount, accounting for $44.98 \%$ of the whole city's assembly power, and outline lighting is just second to it, accounting for $25.63 \%$. All these reflect that architectures are playing an important role in the construction of Shanghai night scene. Specially, buildings acting as the carriers of urban landscape lighting can highlight Chinese culture's classicality and elegance and international metropolis's modernization and fashion.

\subsection{Social attributes}

Firstly, social participation in landscape lighting supply presents a situation of gradually promotion, focusing on absorbing social capital, which can be confirmed from the constitution of landscape lighting's construction investment (see Figure 4) and the distribution of different landscape lighting's property rights (see Figure 5). And at present, $75.44 \%$ of Shanghai's landscape lighting is paid by public finance, of which $74.04 \%$ is full payments by public finance, and $1.40 \%$ is subsidies from government, while $24.56 \%$ by social capital, which means supported by business, enterprise and other private sectors.

Moreover, in the operation, government welcomes social participation through subsidies, namely guide social groups, office buildings, shops, etc. to participate in the landscape lighting projects, such as 'lighting from interior lights', 'window translucent' and so on, promoting long-term operation of these lights through mechanisms like electric charge reduction or exemption. For example, in 
Table 2. Characteristics of Shanghai's different landscape lighting groups

\begin{tabular}{lll}
\hline Landscape lighting groups & Representative & Characteristic \\
\hline & & These architectures have distinct \\
& local features. Using miniwatt \\
& spotlights can create a stereo \\
effect, reflecting its great fasci- & nation and charm. Its dominant \\
Modem European-style & hue chooses golden yellow to \\
architecture & highlight the prosperity of this \\
floodlighting group & financial street.
\end{tabular}

\begin{tabular}{ll}
\hline & \\
& \\
Modem advanced & $\begin{array}{l}\text { Xujiahui Area, } \\
\text { commercial }\end{array}$ \\
and office building & Lujiai Road, \\
lighting group & Nanjing Road
\end{tabular}

These large-scale modem buildings have simple and clear styles. Using large-area external lighting or lighting from interior lights to make the whole building appear crystalline, embodying its characteristic of being straight and tall.

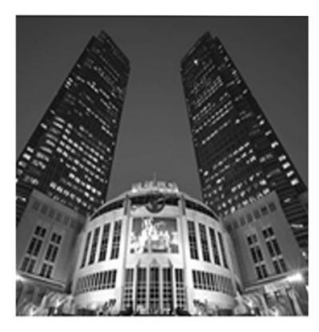

Chinese classical

architecture

lighting group
Yu Garden

Yu Garden

Using the method of traditional silhouette outline by small mini watt spotlights from different angles to light up the roof, pillars, etc, to highlight the classical beauty and recreate the ancient magnificent residence. Meanwhile, hanging red lanterns further show the antique and lingering charm.

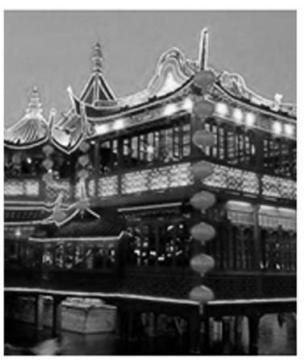

Exploit the function and features of the landmark building to create its unique night lighting. For example, Oriental Pearl TV Tower is wholly illuminated with mainly white light, fully demonstrating the tower's enchantment.

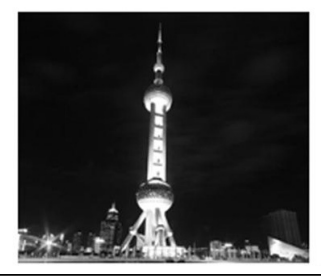

Green land with elegant lighting brings a piece of quiet to the city

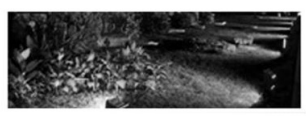

Source: The authors. 
Huangpu District and Pudong New District, some businesses with self-built landscape lighting can be rewarded half of the basic electricity price as subsidies.

Secondly, urban landscape lighting has become a part of people's lives, and its public property needs the public participation. According to the questionnaire of Shanghai Huangpu River Landscape and Lighting Assessment, in terms of

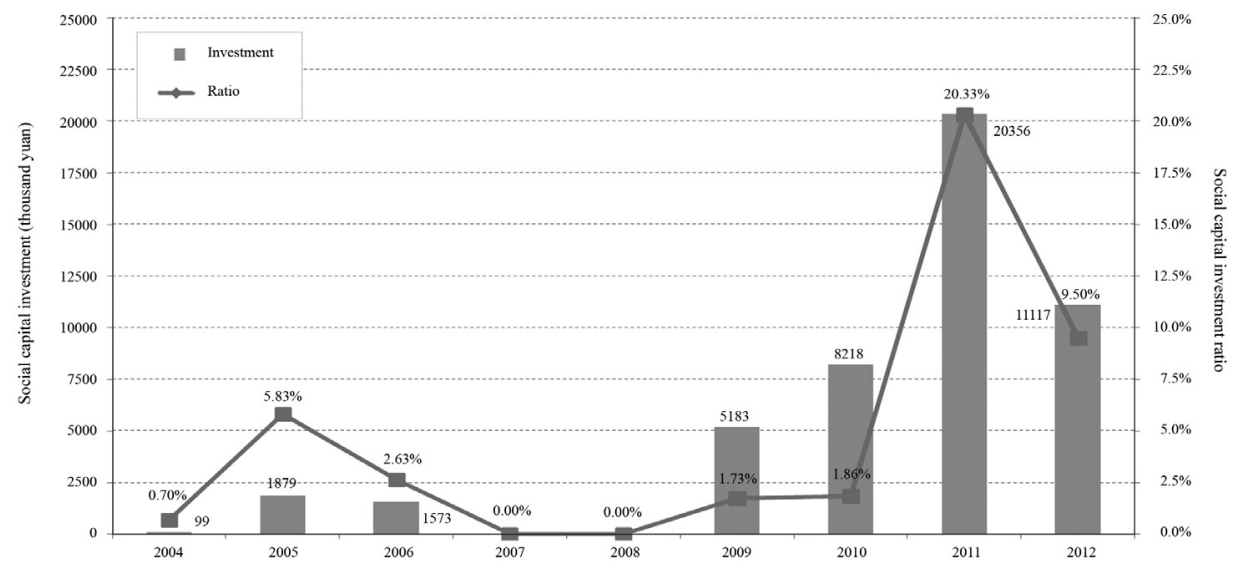

Figure 4. Social capital investment of Shanghai's landscape lighting, covering all the 17 districts and counties, 2004-2012

Source: The authors; data from questionnaire of Shanghai Landscape Lighting's Performance Evaluation \& Long-term Operating Mechanism Survey, including all the 17 districts and counties.

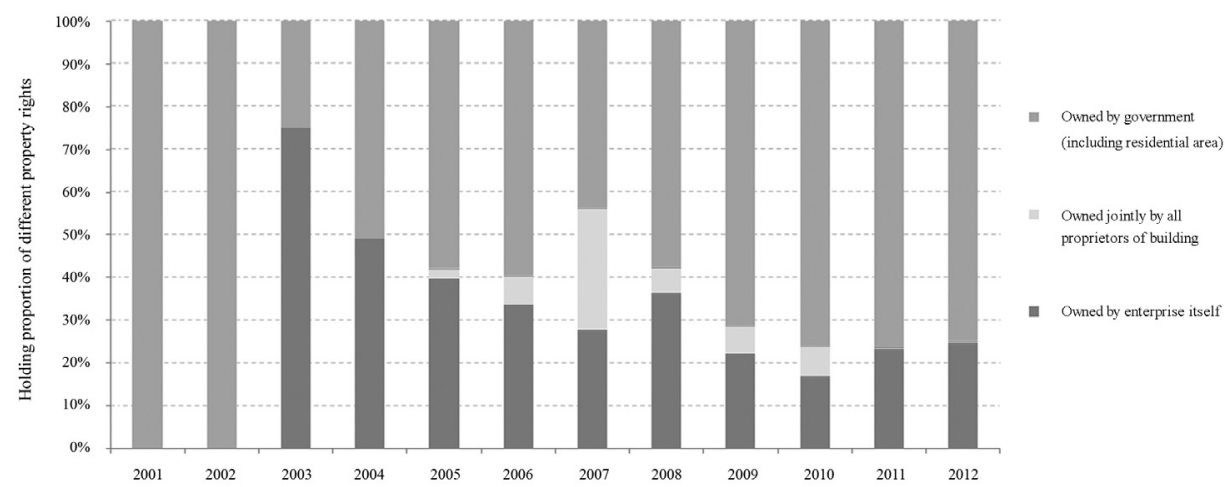

Figure 5. Proportion of Shanghai's landscape lighting ownerships with different property rights, 2001-2012

Source: The authors; data from questionnaire of Shanghai Landscape Lighting's Performance Evaluation \& Long-term Operating Mechanism Survey, including all the 17 districts and counties. 


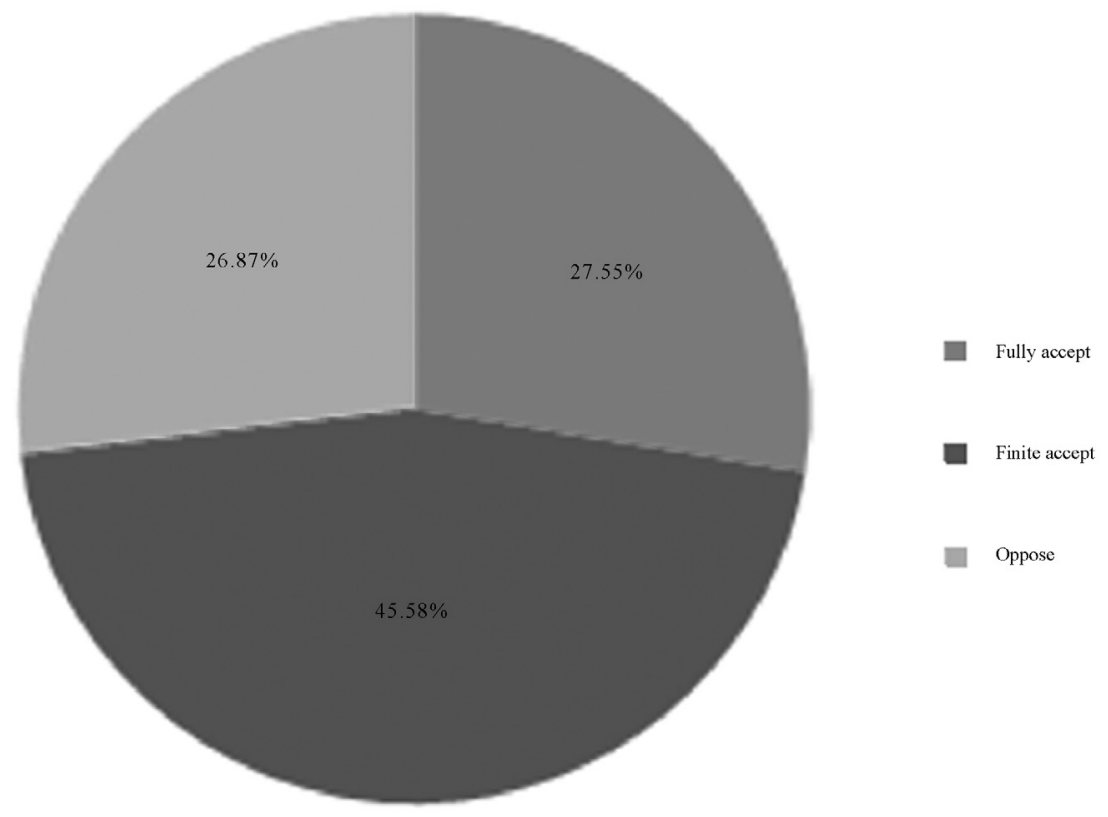

Figure 6. Acceptance on the suggestion of 'turning off lights along Huangpu River'

Source: The authors; data from questionnaire of 'Shanghai Huangpu River Landscape and Lighting Assessment', Shanghai Landscape Lighting's Performance Evaluation \& Long-term Operating Mechanism Survey.

travel period, the number of respondents to choose day and night are, respectively, $31.75 \%$ and $68.25 \%$, it is thus clear that night is the relatively better time to visit Huangpu River; in terms of travel targets, $43.4 \%$ choose Huangpu River nightscape, ranking first, even exceeding the Bund architectures and Lujiazui modern urban landscape (20.6\%). Respondents also evaluated Huangpu River banks' landscape elements (out of 5 points): landscape (4.34) is second only to architectures (4.53), higher than others like the People's Square, sculptures, greenery, cruises and so on. A summary of respondents' views on 'turning off lights along Huangpu River' can be seen in Figure 6: where 73\% cannot fully accept the idea, among whom $46 \%$ consider that lights can be closed in very hot weather and electricity supply difficult periods, and other times should light up. The other $27 \%$ believe that as the embodiment of Shanghai's international metropolis image, the Bund landscape lighting should not be turned off at any time. These results reflect that landscape lighting occupies an important position in people's mind, even from different points of view. 


\subsection{Ecological attributes}

From the perspective of urban economy and tourism, landscape lighting is an essential input for economic development and tourism infrastructure, and it should be given basic guarantee of construction and operation (Marangon and Tempesta 2008). But from the perspective of energy conservation and environment protection, landscape lighting is associated with 'wasting energy' due to the highstandard assembly power of its lamps (Wang 2005).

With the concern on low-carbon and energy conservation, and high electricity demand from all industries and residents in peak seasons, a higher requirement on reducing energy consumption on landscape lighting has been raised. Quantified indexes such as brightness, color, etc. should be in accordance with the requirements of energy-efficient and green-initiative (Li 2012).

Shanghai has made great efforts in the practice of 'green lighting'. In the early 90 's of $20^{\text {th }}$ century, Shanghai government started the green lighting project, and created energy-saving lamps which led to the development of large scale production of energy-saving lamps and other equipment (Liu and Gao 2006). Then in 1998, Shanghai built the landscape lighting monitor centre for the purpose of efficient management, using wireless communication and computer automation technology to achieve unified control which enabled reduction in emission and energy use (CIES et al. 2002). With the development of energy-saving technology, especially the widespread use of LED technology, energy consumption of landscape lighting has been substantially reduced. Furthermore this technology has also stimulated technical innovation of the lighting industry. For instance, in the Oriental Pearl TV Tower's landscape lighting renovation project in 2003, Shanghai took the lead in using LED as light source, which has become a demonstration of successful large scale urban landscape lighting application of LED in China (Wang 2013). In 2008 to 2009, Shanghai saved 500 million kwh of electricity and reduced 0.5 million tons of carbon dioxide through the promotion of 9.42 million efficient lights (Zong 2010). Also, the Bund took the measures like replacing landscape lights to save energy by more than $20 \%$ (data from the survey); Jingan District changed 98\% lamps to LED during 2010 World Expo (data from the survey), etc.

\section{SUMMARY OF THE FINDINGS}

First of all, Shanghai's landscape lighting has been guided and led by the government, who has paid attention to Shanghai's cultural development from the beginning. Specifically, Shanghai's landscape lighting has undergone a rapid de- 


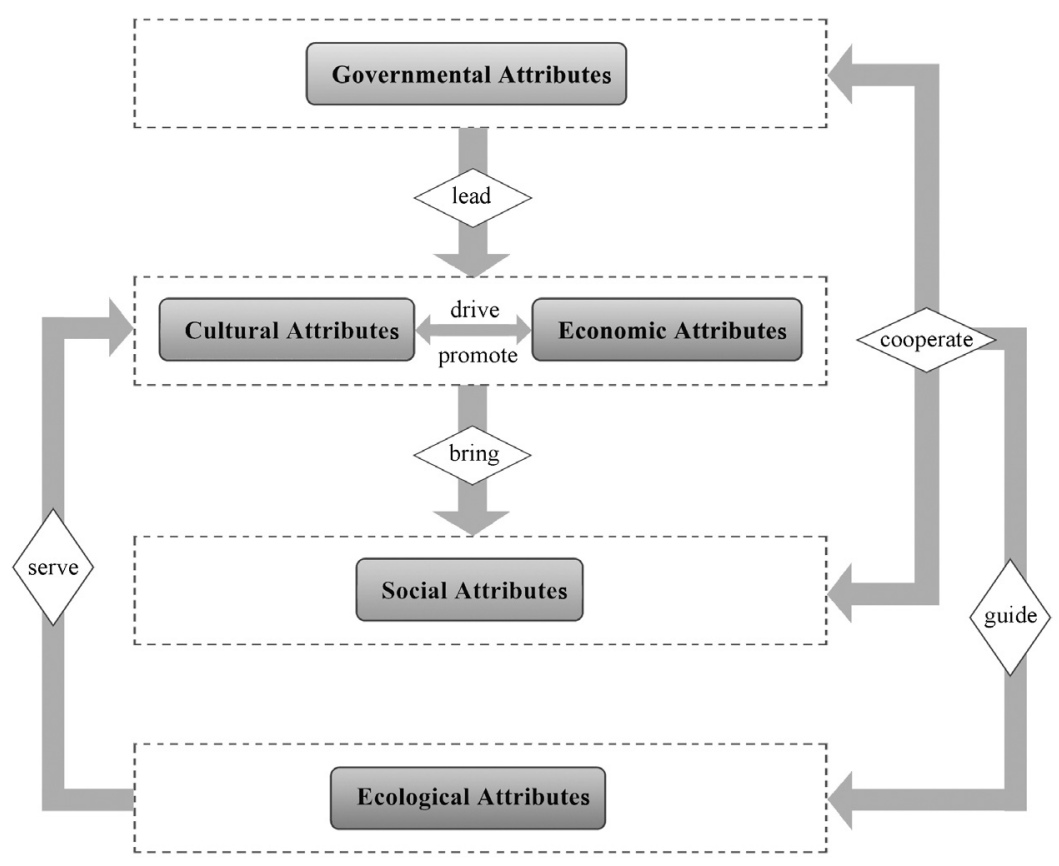

Figure 7. Relationship of Shanghai's landscape lighting's attributes, which are governmental, cultural, economic, social and ecological attributes

Source: The authors.

velopment from nothing, then to a small scale and then to covering the whole city. As one of the achievements of China's reform and opening up, landscape lighting's unique style reflects Shanghai's image and Haipai culture, and further promotes the charm of the international metropolis to the world, and strengthening its brand.

As its nightscape has become a famous brand of Shanghai, it brought new opportunities for the city's economic development, and therefore has made an essential contribution to Shanghai's tourism and service industry (Wang 2010). For the purpose of image shaping and tourism promotion, the city of Shanghai is implementing lighting decoration on both sides of Huangpu River, buildings, and bridges, highlighting their design characteristics through lights (Shanghai Tourism Bureau 2012).

Furthermore, its economic attributes also promotes its cultural ones. Although landscape lighting can give a big boost to the economic development, it needs a large amount of capital investment. That is when the social attributes become 
important. As an example, in Nanjing Road, Huaihai Road and other commercial streets, the market mechanism is put to work by combining landscape lighting and outdoor advertising. This pattern of 'business supports lighting, lighting promotes business' cannot only increase commercial street prosperity, but also drive the development of Shanghai's night market.

Last but not least, restricted by environmental factors in recent years, ecological challenges have gradually been met which has contributed to a sustainable development of landscape lighting.

In summary, the five distinctive characteristics of Shanghai's landscape lighting are closely related, forming a sustainable development model of landscape lighting. Economic and ecological factors as well as cultural and social factors are important for the sustainability of landscape lighting, and all these cannot exist without government leadership (see Figure 7).

\section{CONCLUSION AND REFLECTION}

Shanghai's landscape lighting still needs to improve further and mechanism should be innovated, for example, to strengthen the involvement of private capital, to coordinate government and social market, etc. Its characteristics of 'according to local conditions, reflect local cultures, paying attention to the environment, and bringing forth the new through the old' can provide some implications for other cities in some extent:

(1) The development of urban landscape lighting should deal well with the relationship with urban character. Every city has its character, and unique orientation, only landscape lighting matching that character can highlight a city's personality. It must be well planned under the guidance of government. Shanghai government leads the planning, and there are three priority principles from the level of overall planning (CIES et al. 2002): to give preference to crowded areas and sections (e.g. important commercial streets), to give preference to areas and sections with more domestic and foreign guests (e.g. scenic spots, window units), to give preference to famous areas and buildings (e.g. central square, City Hall, famous enterprises, important landmark buildings, etc.); and also emphasizes the coordination with urban function orientation and surrounding environment from the sector planning level.

(2) The development of urban landscape lighting should have a healthy relationship with urban economy, culture, ecology, etc. Urban landscape lighting is the historical product of a city's social and economic development. In a sense, it incorporates governmental, economic, cultural, scientific, and technological fields. Urban nightscape construction should be coordinated with the city's social 
and economic development direction, strengthen the market and social participation under the leadership of government, and all parties participate within their own boundaries. Then finally it is possible to achieve unity of social, economic and environmental benefits.

(3) The lighting of urban landscape should emphasize the 'urban operation' idea, and understand correctly its position of tourism industrial infrastructure. Firstly, based on the governmental reform goal of 'limited, effective and outstanding government', it is important to clear its responsibility of macroeconomic regulation and control, and to achieve orderly supervision and management through planning and regulations. Secondly, through the establishment of evaluation standards, systems and mechanisms, it should minimize light pollution and energy consumption, realizing the integration of urban image and the promotion of social and economic growth. Thirdly, it is also necessary to have clear government, market and social boundaries, and to give full play to the regulatory role of the market mechanism in its construction and operation through system innovation. In summary, it is essential to construct a long-term operating mechanism to incentive both market and social normative participation in landscape lighting's development, realizing the common construction and collaborative management of government, market and society, and ultimately achieve the sustainable development of urban landscape lighting.

\section{ACKNOWLEDGEMENT}

This research was supported by a grant from the Shanghai Greening and City Appearance Bureau, Shanghai Government.

\section{REFERENCES}

Chen, Y. (2010). Bright points of Shanghai Expo Ceremony, article published in People's Daily Online, 1 May. http://2010.people.com.cn/GB/11502144.html (accessed 8 September 2014).

China Illuminating Engineering Society (CIES), Beijing Municipal Administration Commission, Beijing Sports Bureau, Philips lighting China Co. Ltd. (2002). Shanghai landscape lighting's development and management. Seminar Presentations of Urban Night Lighting and Sport Venues Lighting Technology, 6-12.

Dubovecak, V. (2010). City lighting - European trends and Croatian situation. Univ Zagreb Fac Architecture, 18, 204-217.

Gao, L. (2007). Urban Nightscape Economy. Tianjing, Tianjing University Press.

Granger, C.W.J. (1969). Investing casual relations by econometric models and cross-spectral method. Econimetrica, 37, 424-438. 
Guo, Q., Lin, M.Z., Meng, J.H. and Zhao, J.L. (2011). The development of urban night tourism based on the nightscape lighting projects. A case study of Guangzhou. Energy Procedia, 5, 477-481.

Henderson, J.V., Storeygard, A. and Weil, D.N. (2010). Measuring economic growth from outer space. American Economic Association, 102, 994-1028.

Jiang, D.J. (2006). Discussion on Haipai culture and architecture. Anhui Architecture, 4, 39-40.

Li, N. (2012). Urban Lighting Master Planning and the Cases. Beijing, Posts \& Telecom Press.

Liu, H. and Gao, F. (2006). The new trends of global green lights programme. China Illuminating Engineering Journal, 2, 6-10.

Lu, L.S. (1998). Shanghai lights up. Shanghai Archives, 5, 22-24.

Marangon, F. and Tempesta, T. (2008). Proposta di indicatori economici per la valutazione del paesaggio. EstimoTerritorio, 5, 40-55.

Pang, H. and Chen, S.Y. (1999). The effectiveness and application of Granger Causality Test. Statistical Research, 11, 42-46.

Shanghai Statistical Bureau (2002-2013). Shanghai Statistical Yearbook. Shanghai, Shanghai People Press.

Shanghai Tourism Bureau (2012). $12^{\text {th }}$ Five-year Planning of Shanghai Tourism, Shanghai, Shanghai Government Press.

Wang, Q. (2010). China-Britain City Night Landscape Economy Comparison and Research. Tianjing, Tianjing University Press.

Wang, Q.Q. (2013). A Research on the Tourism Value of TV Tower. Guangzhou, Guangzhou University Press.

Wang, S.W. (2005). Study on Quality and Application of Landscape Lighting Luminaries. Beijing, Tsinghua University Press.

Willis, K.G., Powe, N.A. and Garrod, G.D. (2005). Estimating the value of improved street lighting: a factor analytical discrete choice approach. Urban Studies, 42, 2289-2303.

Xiao, Z.T. (2006). Shanghai Six-Party Talks, article published in CRI Online, 14 June. http://gb.cri. cn/8606/2006/06/14/1806@1089499.htm (accessed 15 September 2014).

Yi, H.W. (2006). Discussion on how to do Granger Causality Test. Journal of Zhongnan University of Economics and Law, 5, 34-36.

Zong, B. (2010). Comprehensively advancing in green lighting project in Shanghai, article published in China Construction Newspaper Online, 1 January. http://www.chinajsb.cn/gb/content/ 2010-01/26/content_300449.htm (accessed 15 September 2014). 